Published in final edited form as:

Dent Clin North Am. 2014 April ; 58(2): 281-297. doi:10.1016/j.cden.2013.12.002.

\title{
Recurrent Aphthous Stomatitis
}

\author{
Sunday O. Akintoye, BDS, DDS, MS ${ }^{\star}$ and Martin S. Greenberg, DDS, FDSRCS ${ }^{\star \star}$ \\ "Associate Professor of Oral Medicine, School of Dental Medicine, University of Pennsylvania \\ ${ }^{* *}$ Professor of Oral Medicine and Associate Dean for Hospital and Extramural Affairs, School of \\ Dental Medicine, University of Pennsylvania
}

\begin{abstract}
Recurrent Aphthous Stomatitis (RAS) is the most common ulcerative disease affecting the oral mucosa. It occurs mostly in healthy individuals and has atypical clinical presentation in immunocompromised individuals. The etiology of RAS is still unknown, but several local, systemic, immunologic, genetic, allergic, nutritional, and microbial factors, as well as immunosuppressive drugs, have been proposed as causative agents. Clinical management of RAS is based on severity of symptoms, frequency, size and number of lesions using topical and systemic therapies. The goals of therapy are to decrease pain and ulcer size, promote healing and decrease frequency of recurrence.
\end{abstract}

\section{Keywords}

Aphthous; Immunological; Crohn's disease; Behçet's disease; Nutritional deficiency;

Psychological stress; Topical therapy; Systemic therapy

\section{Introduction}

Recurrent aphthous stomatitis (RAS) remains the most common ulcerative disease of the oral mucosa presenting as painful round shallow ulcers with well-defined erythematous margin and yellowish-gray pseudomembranous center ${ }^{1}$. RAS has a characteristic prodromal burning sensation that lasts from 2 to 48 hours before an ulcer appears. It occurs in otherwise healthy individuals and is typically located on the buccal and labial mucosa and tongue. Involvement of the heavily keratinized mucosa of the palate and gingiva is less common.

Diseases which also cause oral ulcers that may be mistaken for RAS include Behçet's disease, cyclic neutropenia, recurring intraoral herpes infections, HIV-related oral ulcers or gastrointestinal diseases such as Crohn's disease and ulcerative colitis. It is incumbent upon the clinician managing oral disease to distinguish localized RAS from ulcers caused by an underlying systemic disorder.

Several factors have been proposed as possible causative agents for RAS. These include local factors, such as trauma in individuals who are genetically susceptible to RAS, microbial factors, nutritional factors, such as deficiency of folate and B-complex vitamins,

(C) 2013 Elsevier Inc. All rights reserved.

Publisher's Disclaimer: This is a PDF file of an unedited manuscript that has been accepted for publication. As a service to our customers we are providing this early version of the manuscript. The manuscript will undergo copyediting, typesetting, and review of the resulting proof before it is published in its final citable form. Please note that during the production process errors may be discovered which could affect the content, and all legal disclaimers that apply to the journal pertain. 
immunologic factors, psychosocial stress, and allergy to dietary constituents ${ }^{1}$. Extensive research has focused predominantly on immunologic factors, but a definitive etiology of RAS has yet to be clearly established.

RAS is classified into minor, major, and herpetiform ulcers. More than $85 \%$ of RAS presents as minor ulcers that are less than $1 \mathrm{~cm}$ in diameter and heal without scars (Fig. 1). Ulcers classified as major RAS, also known as Sutton's disease or periadenitis mucosa necrotica recurrens, are larger than $1 \mathrm{~cm}$ in diameter, persist for weeks to months, and heal with scars (Fig. 2). Herpetiform ulcers are clinically distinct because they appear as clusters of multiple ulcers scattered throughout the oral mucosa; despite the name, these lesions have no association with herpes simplex virus. General characteristics of the three types of RAS are summarized in Table 1.

Management of RAS depends upon the frequency and severity of the lesions. Most cases can be adequately managed with topical therapy, but systemic therapy is sometimes indicated for patients with major RAS or those who experience large numbers of minor lesions that are non-responsive to topical therapies.

\section{Epidemiology}

Approximately $20 \%$ of the general population is affected by RAS, but incidence varies from $5 \%$ to $50 \%$ depending on the ethnic and socioeconomic groups studied ${ }^{2,3}$. The prevalence of RAS is influenced by the population studied, diagnostic criteria, and environmental factors ${ }^{1}$. In children, prevalence of RAS may be as high as $39 \%$ and is influenced by the presence of RAS in one or both parents ${ }^{4}$. Children with RAS-positive parents have a $90 \%$ chance of developing RAS compared with $20 \%$ of those with RAS-negative parents ${ }^{2}$. In children of high socioeconomic status, RAS is five times more prevalent and represents $50 \%$ of oral mucosal lesions in this cohort ${ }^{5,6}$. RAS prevalence was found to be higher (male, 48.3\%; female, 57.2\%) among professional school students than in the same subjects 12 years later when they had become practicing professionals. This finding led some investigators to theorize that stress during student life is a major factor in RAS, although the differences due to age changes should also be considered. The onset of RAS appears to peak between the ages of 10 and 19 years and becomes less frequent with advancing age, geographic location or gender ${ }^{7}$. If RAS begins or significantly increases in severity after the third decade and well into adult life (see Table 1), it should increase suspicion that the etiology of the condition maybe attributed to an underlying medical disorder such as hematologic, immunologic, connective tissue disease, or Behçet's syndrome.

\section{Predisposing etiologic factors}

The etiology of RAS lesions is still unknown, but several local, systemic, immunologic, genetic, allergic, nutritional, and microbial factors have been proposed as causative agents. Also, some medications including immunosuppressive drugs such caclineurin and mTOR inhibitors have been associated with severe aphthous-like stomatitis ${ }^{8,9}$ (Table 2).

\section{Local factors}

Local trauma is regarded as a causative agent for RAS in susceptible individuals ${ }^{10,11}$. Trauma predisposes to RAS by inducing edema and early cellular inflammation associated with an increased viscosity of the oral submucosal extracellular matrix ${ }^{12}$. Not all oral trauma leads to RAS, because denture wearers do not have a high prevalence of RAS in spite of the fact that this cohort is three times more susceptible to oral mucosal ulceration ${ }^{13}$. In addition, habitual smokers who constantly expose their oral mucosa to nicotine have demonstrated a negative association between smoking and RAS ${ }^{14-16}$ Therefore, local trauma apparently 
predisposes to RAS only in those individuals who have a hereditary predilection for the disease.

Some changes in salivary composition, such as $\mathrm{pH}$, that affect the local properties of saliva and a stress-induced rise in salivary cortisol have been correlated with RAS ${ }^{17,18}$. Although direct association of salivary gland dysfunction with RAS has not been demonstrated ${ }^{19}$, patients with a combination of RAS and xerostomia may experience increased symptoms due to the increased oral dryness.

\section{Microbial factors}

Despite the fact that RAS has not been etiologically associated with herpes simplex virus based on several well-designed studies, both laymen and clinicians often confuse RAS with herpes simplex virus (HSV) infection. HSV virons and antigens have neither been identified in aphthous lesions nor successfully isolated in RAS biopsy tissues ${ }^{20,21}$. Although it has been suggested that reactivation of varicella zoster virus (VZV) or human cytomegalovirus (CMV) is associated with frequent recurrence of aphthous ulcers ${ }^{22}$, evaluation of RAS biopsy tissue using polymerase chain reaction (PCR) for possible involvement of HV6, CMV, VZV, Epstein-Barr virus (EBV), as causative factors did not find evidence to support the role of these viruses in RAS pathogenesis ${ }^{20,23}$. Thus, it is the clinician's responsibility to distinguish RAS from herpes infections, reassure RAS patients that they do not have an infectious disease and that antiviral therapy is neither necessary nor effective.

Helicobacter pylori (H pylori), a common risk factor for gastric and duodenal ulcers, has been proposed to have causative role in RAS. Despite the fact that stomach ulcers and RAS are linked to dysregulated immune functions, molecular studies that identified $\mathrm{H}$ pylori in both affected and non-affected mucosa of RAS patients found no association with RAS $^{24,25}$. Interestingly, another study ${ }^{26}$ reported that eradication of $\mathrm{H}$ pylori in RAS patients positively correlated with increased Vitamin B12 levels and decreased number of aphthous lesions ${ }^{26-29}$. There has been considerable speculation regarding the possible involvement of Streptococci species in the etiology of RAS, especially S sanguis 2A. The proposed hypothesis is that oral streptococci act as antigenic stimulants that cross-react with mitochondrial heat shock proteins of oral keratinocytes. This reaction purportedly induces a T-cell-mediated immune response that causes oral mucosal damage ${ }^{30}$, but this theory remains unproven. EBV and lactobacillus are other organisms that have been studied in RAS patients. A study of the possible role of lactobacillus in RAS has yielded no significant finding; but in a small study sample, EBV was associated with epithelial cells of preulcerative RAS 31,32 . Using PCR techniques, $39 \%$ of pre-ulcerative RAS lesions were positive for EB-DNA. Their peripheral blood lymphocytes and serum were also positive for EB-DNA. The report theorized that lymphocytes may serve as a reservoir for latent EBV infection and promote viral shedding into the plasma. However, a causal relationship between EB viral load and RAS was not evaluated.

\section{Underlying medical disease}

The most prominent medical disorder associated with RAS is Behçet's syndrome, characterized by recurring oral and genital ulcers, and eye lesions (Table 2). Behçet's syndrome is a multisystem disorder resulting from vasculitis of small and medium-sized vessels and inflammation of epithelium. The abnormal inflammatory response in Behçet's syndrome is caused by immune complexes induced by $\mathrm{T}$ lymphocytes and plasma cells. Although Behçet's syndrome usually affects adults, a number of cases have been reported in children ${ }^{33-35}$. Since distinguishing RAS from Behçet's disease now depends on clinical criteria, investigators have sought an effective laboratory test. A high titer of antiSaccharomyces cerevisiae antibodies (ASCA) has been detected in Behçet patients 
compared with RAS patients and apparently healthy individuals ${ }^{36}$. The report suggested that ASCA test might be a method to distinguish between these two patient populations. This distinction may not be as simple as reported, because up to $70 \%$ of patients with Crohn's disease and $15 \%$ of patients with ulcerative colitis are ASCA positive and both diseases are associated with recurring oral ulcers. The use of human leukocyte antigen (HLA) system to distinguish RAS from Behçet's disease showed significant differences in frequency of certain HLA antigens, but the distinction between the two disorders is still not clearly defined ${ }^{37}$.

Another variant of Behçet's syndrome that includes relapsing polychondritis, a disorder characterized by mouth and genital ulcers with inflamed cartilage, has been labeled MAGIC syndrome (Table 2) ${ }^{38,39}$.

Inflammatory bowel diseases such as Crohn's disease and ulcerative colitis have been associated with oral ulcers that may resemble RAS, but Crohn's lesions often have indurated borders and are histologically different because of the granulomatous nature of the lesion (Fig 3). Approximately $10 \%$ of patients with Crohn's disease have oral mucosal ulcers, and the oral manifestations occasionally precede intestinal symptoms. Some researchers believe that inflammation of minor salivary glands is a possible cause of the oral ulcers ${ }^{40}$.

Celiac disease, an autoimmune sensitivity to gluten is another medical disorder often associated with RAS, but the causal relationship between these two disorders is not completely clear. Prevalence of RAS in celiac disease patients has been reported to range from $4 \%$ to $40 \%$, but oral ulceration in celiac disease patients also vary from $3 \%$ to $61 \% 41$. In addition, oral ulcerations in celiac disease do not have the distinctive features of RAS and often resolve when celiac disease patients are placed on gluten-free diet. Therefore, oral ulceration in celiac disease patients may not be the typical $\operatorname{RAS}^{42}$.

In HIV-positive individuals, RAS occurs more frequently, lasts longer, and causes more painful symptoms than in healthy individuals (Fig 4). It is also a common finding in HIVpositive children 43,44 . RAS is usually a late finding in AIDS patients with CD4+ lymphocyte counts below 100 cells $/ \mathrm{mm}^{3}$, and it may occasionally be a presenting sign of HIV infection ${ }^{4}$.

Cyclic neutropenia, a rare disorder that presents at childhood, is also associated with recurring oral ulcers during periods when the neutrophil count is severely depressed ${ }^{45}$. Another condition described as periodic fever, aphthous stomatitis, pharyngitis, and cervical adenitis (PFAPA) or Marshall's syndrome has a presentation similar to that of cyclic neutropenia and is commonly associated with oral ulcers that cannot be distinguished from RAS ${ }^{46}$.

\section{Hereditary and genetic factors}

The role of heredity is the best-defined underlying cause of RAS. Susceptibility to RAS is significantly increased by its presence in one or both parents. Studies of identical twins have also demonstrated the hereditary nature of this disorder ${ }^{4}$. Individuals with a positive family history of RAS, tend to develop RAS at an early age. Specifically, children with two RASpositive parents have a $90 \%$ chance of developing RAS that present with more severe symptoms and recur more frequently ${ }^{2}$.

Certain genetically specific HLAs have been identified in RAS patients: HLA-A2, HLA-B5, HLA-B12, HLA-B44, HLA-B51, HLA-B52, HLA-DR2, HLA-DR7, and HLA-DQ series 47. A confounding finding is that certain ethnic groups have been associated with different HLA 
alleles or haplotypes with no HLA consistently associated with RAS ${ }^{47}$. Therefore, additional studies are needed to clarify the variability of RAS in host susceptibility.

\section{Allergic factors}

Allergy has been suspected as a cause of RAS. Hypersensitivity to certain food substances, oral microbes such as Streptococcus sanguis, and microbial heat shock protein have been suggested as possible causative factors, but there is still no conclusive evidence to support allergy as a major cause of RAS ${ }^{48,49}$. Although some studies reported that RAS patients tend to have hypersensitivity to environmental allergens, other reports did not find significant correlation between hypersensitivity and RAS. In one report, patients wearing nickel-based orthodontic appliances developed RAS that coincided with fitting of the appliance. When the appliance was replaced with a nickel-free type, the mucosal lesion regressed. RAS in this population was attributed to the systemic effect of ingested nickel rather than direct contact, because a patch test to nickel sulfate did not reactivate the mucosal ulceration ${ }^{50}$. In patients presenting with refractory cases of RAS and known allergy to food items such as milk, cheese, and wheat, sequential elimination of these dietary items was found beneficial in a small subset of RAS patients, thereby suggesting a possible link between food allergy and some cases of RAS ${ }^{51}$.

The denaturing effect of sodium lauryl sulfate (SLS) commonly found in toothpastes has also been discussed as a cause of RAS. It was proposed that SLS might erode the oral mucin layer, exposing the underlying epithelium, thereby making the individual more susceptible to RAS. This theory still needs further clarification, because it has also been demonstrated that use of SLS-free toothpastes did not affect development of new lesions in RAS patients 52,53 .

\section{Immunologic factors}

There has been significant research on the cause of RAS focusing on detecting an abnormality in the immunologic response. Early work suggested a relationship between several immune-mediated reactions and development of RAS. These include cytotoxicity of T lymphocytes to oral epithelium, antibody-dependent cell-mediated cytotoxicity, and defects in lymphocyte subpopulations $49,54,55$. One theory is that multiple immune reactions cause damage induced by deposition of immune complexes within the oral epithelium. In some patients, an elevated level of sIgA has been reported during acute and remission phases of minor RAS ${ }^{56}$. Some other studies have shown an association between RAS severity and abnormal proportions of CD4+ and CD8+ cells, alteration of the CD4+: CD8+ ratio ${ }^{57,58}$, and increased levels of several cytokines including interleukin 2 (IL-2), interferon gamma (INF- $\gamma$ ), and tumor necrosis factor- $\alpha$ (TNF- $\alpha$ ) mRNA in RAS lesions ${ }^{59,60}$. Immunohistochemical studies of RAS biopsy tissues demonstrated numerous inflammatory cells with variable ratios of CD4+: CD8+ T lymphocytes depending on the ulcer duration. CD4+ cells were more numerous during the pre-ulcerative and healing stages, whereas CD8+ cells tended to be more numerous during the ulcerative state of the ulcer. Interestingly, studies on non-affected sites were negative, making researchers focus more on the theory that RAS may be caused by an antigen-triggering effect. Since levels of serum immunoglobulins and natural killer cells are essentially within normal limits in RAS patients, the focus is still on a dysregulated local cell-mediated immune response conducive to accumulation of subsets of T-cells, mostly CD8+ cells. This local immune response is thought to cause tissue breakdown that eventually manifests as RAS.

\section{Nutritional factors}

The role of nutritional deficiency as a cause of RAS has been highlighted by the association of a subset of 5\% to $10 \%$ of RAS patients with low serum levels of iron, folate, zinc, or 
vitamins B1, B2, B6 and B12. This is an indication that nutritional deficiency is apparently an etiological factor for RAS 61,62 . Some of these nutritional deficiencies may be secondary to other diseases such as malabsorption syndrome or gluten sensitivity associated with or without enteropathy. Hematologic screening of RAS patients for anemia or deficiency of iron, folate, and B vitamins is appropriate for patients with major RAS or cases of minor RAS that worsen during adult life. A deficiency of calcium and vitamin $\mathrm{C}$ has also been proposed in patients with RAS, but these findings were in association with vitamin B1 deficiency, supporting the idea of combined nutritional deficiency in RAS patients ${ }^{63}$. The recovery of some RAS patients after treatment of the nutritional deficiency has further corroborated the causative role of nutritional deficiency in a subset of RAS patients ${ }^{64,65}$.

\section{Psychological stress}

Stress and psychological imbalance have been associated with $\mathrm{RAS}^{6,10,66}$. Stressful life events can increase the chances that a RAS susceptible patient will develop a new lesion. One study reported that mental stress is strongly associated with episodes of RAS more than physical stress; and these stressful events tend to correlate more with onset of RAS rather than duration of the lesions ${ }^{10}$. In women, appearance of RAS may coincide with menses; and stress of academic load may be the precipitating factor for the higher prevalence of RAS in professional school students ${ }^{63}$. A clinician should consider questioning patients with worsening episodes of RAS regarding psychosocial, physical or environmental stress.

\section{Other factors}

The role of antioxidants in RAS is still attracting attention because blood and salivary levels of antioxidants such as erythrocyte superoxide dismutase and catalase seem to be higher in patients with RAS and Behçet's syndrome than in normal controls ${ }^{67-69}$, but their causative roles in RAS are yet to be clearly defined. There have also been several reported cases of drug-induced RAS. A case-control study associated a higher risk of RAS with drug exposure and found significant association with nonsteroidal anti-inflammatory drugs and betablockers ${ }^{70}$. Nicorandil, a vasodilator used extensively outside the United States to manage angina as well as caclineurin and mTOR inhibitors used as immunosuppressors have been associated with severe aphthous-like ulcers $8,9,71$. Therefore, it is imperative to closely scrutinize the medication history as well as current medications of RAS patients to identify any pattern associated with frequency and duration of RAS lesions.

\section{Clinical manifestation and pathogenesis}

RAS patients usually experience prodromal burning sensations that last from 2 to 48 hours before an ulcer appears. Ulcers are round with well-defined erythematous margins and a shallow ulcerated center covered with yellowish-gray fibrinous pseudomembrane. RAS ulcers usually develop on non-keratinized oral mucosa, with the buccal and labial mucosa being the most common sites, and last approximately 10 to 14 days without scar formation (see Table 1). The oral ulcers seen in Behçet's disease are clinically similar, but they are more likely to be major aphthae ${ }^{72}$. Microscopic characteristics of RAS are non-specific. The pre-ulcerative lesion demonstrates subepithelial inflammatory mononuclear cells with abundant mast cells, connective tissue edema and lining of the margins with neutrophils ${ }^{73}$. Damage to the epithelium usually begins in the basal layer and progresses through the superficial layers, leading eventually to ulceration and surface exudate. The presence of extravasated erythrocytes around the ulcer margin, subepithelial extravascular neutrophils, numerous macrophages loaded with phagolysosomes, and the non-specific binding of stratum spinosum cells to immunoglobulins and complements may be a result of vascular leakage and passive diffusion of serum proteins. These findings suggest that pathogenesis of RAS may be mediated by immune complex vasculitis ${ }^{74}$. The onset of a RAS lesion is 
associated with cell-mediated immune response, generation of $\mathrm{T}$ cells and production of TNF-a. Peripheral blood mononuclear cells of RAS patients has been shown to secrete high amounts of TNF- $a$, an indication that TNF-a plays a key role in RAS pathogenesis ${ }^{54,74-76}$. Consequently, TNF-a-mediated endothelial cell adhesion and neutrophil chemotaxis initiate the cascade of inflammatory processes that lead to ulceration ${ }^{77}$. Majority of the TNF- $a$ is produced in response to activation of toll-like receptors (TLRs), a set of functional membrane receptors associated with immune response and protection of epithelial barrier. TLRs have both pro- and anti-inflammatory properties. While pro-inflammatory TLRs were found to be greatly increased in the epithelium and lamina propria of RAS lesions in some patients ${ }^{78}$, a decrease in expression levels of TLRs with anti-inflammatory activities was also found in another cohort of RAS patients ${ }^{79}$. Therefore, the role of TLRs in RAS pathogenesis still needs to be better defined, but it is possible that an imbalance in pro- and anti-inflammatory activities of TLRs could increase susceptibility to RAS in some individuals.

\section{Management}

The proper treatment of RAS depends on the severity of symptoms, frequency, size, and number of the ulcers. Patients who experience occasional episodes of minor aphthous ulcers experience significant relief with appropriate topical therapy. Symptoms resulting from occasional small lesions are often adequately controlled with use of a protective emollient such as Zilactin (Zila Pharmaceuticals, Phoenix, Arizona) or Orabase (Bristol Myers Squib, Princeton, New Jersey), used either alone or mixed with a topical anesthetic such as benzocaine. Other topical agents that can minimize patient discomfort include diclofenac, a nonsteroidal anti-inflammatory drug, or amlexanox paste, which has been shown to decrease the healing time of minor aphthae ${ }^{80,81}$. Patients can also get some pain relief by swishing 3 to 4 times a day with Magic Mouth Wash (MMW), which can be custom-mixed by the pharmacy. Several formulations of MMW are available, but the most common is a mixture of equal parts of viscous lidocaine, diphenhydramine and Maalox or similar antacid.

In patients with more frequent or more severe disease, use of a topical glucocorticoid is an effective therapy to decrease both the size and healing time of the ulcers, especially when the medication is used early in the developing stage of the lesion. ${ }^{82,83}$ Patients should be counseled regarding the proper use of high-potency topical steroids and instructed to apply medication sparingly on the mucosal areas involved. This precaution will significantly decrease the risk of developing local and systemic side effects. Some clinicians advocate mixing high-potency steroids with an adhesive such as Orabase to promote contact between the lesion and medication. When patients have large, slowly healing lesions of major RAS, topical steroids may not be effective, so the use of intralesional steroid injections may help decrease the healing time.

Topical antibiotics have been advocated as therapy for RAS ${ }^{84}$. Tetracycline mouth rinses have been reported to decrease both the healing time and the pain of the lesions in several trials, but the association of these rinses with oral candidiasis and reports of allergic reactions have limited the use of this form of therapy. The effectiveness of topical tetracycline may result from a combination of the anti-bacterial and the anti-inflammatory effects of this group of antibiotics. A placebo-controlled study of the topical use of penicillin $\mathrm{G}$ troches to treat minor RAS showed efficacy in reducing both pain and healing time of RAS ${ }^{85}$. The risk of allergic reactions from this potentially useful form of therapy has not been reported, even in studies involving large numbers of RAS patients.

Topical therapy is effective treatment for most patients with RAS; however, topical therapy alone does not decrease the formation of new lesions and may not be adequate treatment for 
patients with major RAS or patients who experience frequent episodes of multiple minor RAS. Systemic therapy should be considered for this relatively small group of patients, but the potential benefit of the drug should always be carefully weighed against potential side effects, and systemic therapies should be used only by clinicians trained in their use.

A short course of systemic corticosteroids such as prednisone may occasionally be used to treat a particularly severe episode of major RAS, but long-term use of systemic steroids is rarely indicated for RAS because the serious side effects of long-term steroid therapy outweigh the benefits for RAS patients ${ }^{86}$.

Clinicians who treat patients with major RAS have been searching for a substitute for systemic corticosteroids that will prevent formation of new RAS lesions and lower incidence of serious side effects. Medications that have been reported to have potential effectiveness in reducing the formation of new RAS lesions include pentoxifylline (PTX), colchicine, dapsone and thalidomide ${ }^{87}$.

PTX, a methylxanthine related to caffeine, has been used for many years to treat intermittent leg cramps in patients with peripheral vascular disease. PTX improves the circulation of blood to the extremities by increasing the flexibility of red blood cells, making it easier for them to physically pass through atherosclerotic vessels. PTX has also been shown to decrease inflammation by its effect on white blood cell function and inflammatory cytokines, making it a useful therapy for inflammatory diseases such as rheumatoid arthritis, vasculitis, and diabetic leg ulcers. There have been several clinical reports of the successful use of PTX, $400 \mathrm{mg}$ three times/day, to manage RAS. Patient with major RAS treated with PTX tend to have fewer and smaller ulcers and significant pain reduction without major side effects (Fig 5) ${ }^{87,88}$.

Another drug that has been advocated for management of major RAS is colchicine, which has been used for decades to manage gouty arthritis. Because colchicine has antiinflammatory activity and inhibits the cell-mediated response, it has proven useful in the management of a number of dermatologic diseases including psoriasis, Behçet's syndrome, dermatitis herpetiformis, and leukocytoclastic vasculitis. ${ }^{89}$ There are still no controlled clinical trials of colchicine therapy for RAS, but open trials have shown encouraging results 87,90 . Low doses of colchicine $0.6-1.2 \mathrm{mg} /$ day have been shown to reduce number and duration of aphthous lesions, therefore long term therapy with $1.2-1.8 \mathrm{mg} / \mathrm{day}$ is often recommended ${ }^{91}$. Colchicine has a low therapeutic-toxicity window because of myelosuppression, hepatoxicity, decreased sperm count and adverse drug interactions ${ }^{8}$. Before starting colchicine therapy, baseline liver function tests and hematology screening of RAS patients should be performed and monitored frequently. Also, careful medication history should be obtained to avoid adverse drug interactions. Colchicine has been associated with teratogenicity in animal studies but limited adverse fetal and maternal effects reported in human studies were not significantly higher than normal ${ }^{9}$. However, some clinicians still recommend that RAS patients use appropriate contraceptive methods before colchicine therapy ${ }^{91}$

The medication that has been most carefully studied for the management of major RAS is thalidomide, a drug with a long history of major side effects, including severe life threatening and crippling birth defects ${ }^{92}$. Thalidomide was originally marketed in Europe in the 1950s as a non-addicting sedative but was withdrawn from the market when the risk of major teratogenic defects, including phocomelia and neural tube abnormalities, were discovered. Later, investigators discovered its potent anti-inflammatory and immunomodulatory properties, by its ability to inhibit angiogenesis and reduce the activity 
of TNF-a. Due to its effectiveness, limited use of the drug was permitted for patients with recalcitrant diseases such as erythema nodosum leprosum, lupus and Behçet's syndrome ${ }^{93}$.

Controlled clinical trials have demonstrated the effectiveness of thalidomide in treating major RAS in HIV-infected patients and in otherwise normal individuals. Thalidomide therapy results in either complete remission or substantial improvement in a majority of major RAS patients ${ }^{94,95}$. To minimize the risk of birth defects resulting from thalidomide therapy, clinicians prescribing the drug must register in the program for Risk Evaluation and Mitigation Strategy (REMS) formerly known as the STEPS program ${ }^{96}$. This program educates physicians and dentists on the proper use of the drug, provides counseling for patients, and closely monitors thalidomide use. For example, the program mandates that women in childbearing years must use two forms of birth control and have a monthly pregnancy test. Both women and men taking thalidomide must be evaluated every four weeks and both the patient and the prescribing clinician must complete a questionnaire before thalidomide can be prescribed for another 28 days. In addition to birth defects, thalidomide can also cause peripheral neuropathy, neutropenia, and drowsiness ${ }^{97}$.

Other drugs that have been advocated for the management of major RAS not responding adequately to topical therapy include dapsone, a sulfone derivative which is used to manage a number of mucocutaneous disorders; azathioprine, an immunosuppressive drug; and etanercept, a recombinant TNF-soluble receptor that binds to TNF-a to limit the amount of active TNF-a. Etanercept has been used successfully to manage rheumatoid arthritis and psoriasis $^{87,98,99}$

\section{Summary}

RAS is the most common ulcerative disease affecting the oral mucosa. Its etiology is still unknown, occurs mostly in healthy individuals and has a more severe clinical presentation in immunocompromised individuals. Several local, systemic, immunologic, genetic, allergic, nutritional, and microbial factors as well as immunosuppressive drugs have been proposed as causative agents. Clinical management of RAS is aimed at improving patient function and quality of life using topical and systemic therapies. The goals of therapy are to decrease pain and ulcer size, promote healing, and decrease frequency of recurrence.

\section{References}

1. Porter SR, Scully C, Pedersen A. Recurrent aphthous stomatitis. Crit Rev Oral Biol Med. 1998; 9(3):306-321. [PubMed: 9715368]

2. Ship. Epidemiologic aspects of recurrent aphthous ulcerations. Oral Surg Oral Med Oral Pathol. Mar; 1972 33(3):400-406. [PubMed: 4501169]

3. Rogers RS 3rd. Recurrent aphthous stomatitis: clinical characteristics and associated systemic disorders. Semin Cutan Med Surg. Dec; 1997 16(4):278-283. [PubMed: 9421219]

4. Miller MF, Garfunkel AA, Ram CA, Ship. The inheritance of recurrent aphthous stomatitis. Observations on susceptibility. Oral Surg Oral Med Oral Pathol. May; 1980 49(5):409-412. [PubMed: 6929465]

5. Crivelli MR, Aguas S, Adler I, Quarracino C, Bazerque P. Influence of socioeconomic status on oral mucosa lesion prevalence in schoolchildren. Community Dent Oral Epidemiol. Feb; 1988 16(1):5860. [PubMed: 3422621]

6. de Gallo CB, Mimura MA, Sugaya NN. Psychological stress and recurrent aphthous stomatitis. Clinics (Sao Paulo). 2009; 64(7):645-648. [PubMed: 19606240]

7. Ship JA, Chavez EM, Doerr PA, Henson BS, Sarmadi M. Recurrent aphthous stomatitis. Quintessence Int. Feb; 2000 31(2):95-112. [PubMed: 11203919]

8. Terkeltaub RA. Colchicine update: 2008. Semin Arthritis Rheum. Jun; 2009 38(6):411-419. [PubMed: 18973929] 
9. Berkenstadt M, Weisz B, Cuckle H, Di-Castro M, Guetta E, Barkai G. Chromosomal abnormalities and birth defects among couples with colchicine treated familial Mediterranean fever. Am J Obstet Gynecol. Oct; 2005 193(4):1513-1516. [PubMed: 16202748]

10. Huling LB, Baccaglini L, Choquette L, Feinn RS, Lalla RV. Effect of stressful life events on the onset and duration of recurrent aphthous stomatitis. J Oral Pathol Med. Feb; 2012 41(2):149-152. [PubMed: 22077475]

11. Wray D, Graykowski EA, Notkins AL. Role of mucosal injury in initiating recurrent aphthous stomatitis. Br Med J (Clin Res Ed). Dec 12; 1981 283(6306):1569-1570.

12. Stone OJ. Aphthous stomatitis (canker sores): a consequence of high oral submucosal viscosity (the role of extracellular matrix and the possible role of lectins). Med Hypotheses. Dec; 1991 36(4):341-344. [PubMed: 1809853]

13. Espinoza I, Rojas R, Aranda W, Gamonal J. Prevalence of oral mucosal lesions in elderly people in Santiago, Chile. J Oral Pathol Med. Nov; 2003 32(10):571-575. [PubMed: 14632931]

14. Sawair FA. Does smoking really protect from recurrent aphthous stomatitis? Therapeutics and clinical risk management. 2010; 6:573-577. [PubMed: 21151626]

15. Marakoglu K, Sezer RE, Toker HC, Marakoglu I. The recurrent aphthous stomatitis frequency in the smoking cessation people. Clinical oral investigations. Jun; 2007 11(2):149-153. [PubMed: 17273857]

16. Atkin PA, Xu X, Thornhill MH. Minor recurrent aphthous stomatitis and smoking: an epidemiological study measuring plasma cotinine. Oral Dis. May; 2002 8(3):173-176. [PubMed: 12108762]

17. Albanidou-Farmaki E, Poulopoulos AK, Epivatianos A, Farmakis K, Karamouzis M, Antoniades D. Increased anxiety level and high salivary and serum cortisol concentrations in patients with recurrent aphthous stomatitis. Tohoku J Exp Med. Apr; 2008 214(4):291-296. [PubMed: $18441503]$

18. McCartan BE, Lamey PJ, Wallace AM. Salivary cortisol and anxiety in recurrent aphthous stomatitis. J Oral Pathol Med. Aug; 1996 25(7):357-359. [PubMed: 8890048]

19. Maurice M, Mikhail W, Aziz M, Barsoum M. Aetiology of recurrent aphthous ulcers (RAU). J Laryngol Otol. Sep; 1987 101(9):917-920. [PubMed: 3668373]

20. Lin SS, Chou MY, Ho CC, et al. Study of the viral infections and cytokines associated with recurrent aphthous ulceration. Microbes and infection/Institut Pasteur. Apr; 2005 7(4):635-644. [PubMed: 15840465]

21. Woo SB, Sonis ST. Recurrent aphthous ulcers: a review of diagnosis and treatment. J Am Dent Assoc. Aug; 1996 127(8):1202-1213. [PubMed: 8803396]

22. Pedersen A, Hornsleth A. Recurrent aphthous ulceration: a possible clinical manifestation of reactivation of varicella zoster or cytomegalovirus infection. J Oral Pathol Med. Feb; 1993 22(2): 64-68. [PubMed: 8383202]

23. Sun A, Chang JG, Chu CT, Liu BY, Yuan JH, Chiang CP. Preliminary evidence for an association of Epstein-Barr virus with pre-ulcerative oral lesions in patients with recurrent aphthous ulcers or Behcet's disease. J Oral Pathol Med. Apr; 1998 27(4):168-175. [PubMed: 9563572]

24. Victoria JM, Kalapothakis E, de Silva JF, Gomez RS. Helicobacter pylori DNA in recurrent aphthous stomatitis. J Oral Pathol Med. Apr; 2003 32(4):219-223. [PubMed: 12653861]

25. Birek C, Grandhi R, McNeill K, Singer D, Ficarra G, Bowden G. Detection of Helicobacter pylori in oral aphthous ulcers. J Oral Pathol Med. May; 1999 28(5):197-203. [PubMed: 10226941]

26. Tas DA, Yakar T, Sakalli H, Serin E. Impact of Helicobacter pylori on the clinical course of recurrent aphthous stomatitis. J Oral Pathol Med. Jan; 2013 42(1):89-94. [PubMed: 22827585]

27. Maleki Z, Sayyari AA, Alavi K, Sayyari L, Baharvand M. A study of the relationship between Helicobacter pylori and recurrent aphthous stomatitis using a urea breath test. J Contemp Dent Pract. 2009; 10(1):9-16. [PubMed: 19142251]

28. Gisbert JP, Castro-Fernandez M, Perez-Aisa A, et al. Fourth-line rescue therapy with rifabutin in patients with three Helicobacter pylori eradication failures. Aliment Pharmacol Ther. Apr; 2012 35(8):941-947. [PubMed: 22372560] 
29. Albanidou-Farmaki E, Giannoulis L, Markopoulos A, et al. Outcome following treatment for Helicobacter pylori in patients with recurrent aphthous stomatitis. Oral Dis. Jan; 2005 11(1):2226. [PubMed: 15641963]

30. Scully C, Gorsky M, Lozada-Nur F. The diagnosis and management of recurrent aphthous stomatitis: a consensus approach. J Am Dent Assoc. Feb; 2003 134(2):200-207. [PubMed: 12636124]

31. Acar S, Yetkiner AA, Ersin N, Oncag O, Aydogdu S, Arikan C. Oral findings and salivary parameters in children with celiac disease: a preliminary study. Medical principles and practice: international journal of the Kuwait University, Health Science Centre. 2012; 21(2):129-133.

32. Stevenson G. Evidence fo a negative correlation of recurrent aphthous ulcers with lactobacillus activity. J La Dent Assoc. Fall;1967 25(2):5-7. [PubMed: 4966035]

33. Keogan MT. Clinical Immunology Review Series: an approach to the patient with recurrent orogenital ulceration, including Behcet's syndrome. Clin Exp Immunol. Apr; 2009 156(1):1-11. [PubMed: 19210521]

34. Krause I, Uziel Y, Guedj D, et al. Mode of presentation and multisystem involvement in Behcet's disease: the influence of sex and age of disease onset. J Rheumatol. Aug; 1998 25(8):1566-1569. [PubMed: 9712102]

35. Krause I, Rosen Y, Kaplan I, et al. Recurrent aphthous stomatitis in Behcet's disease: clinical features and correlation with systemic disease expression and severity. J Oral Pathol Med. May; 1999 28(5):193-196. [PubMed: 10226940]

36. Krause I, Monselise Y, Milo G, Weinberger A. Anti-Saccharomyces cerevisiae antibodies--a novel serologic marker for Behcet's disease. Clin Exp Rheumatol. Jul-Aug;2002 20(4 Suppl 26):S21-24. [PubMed: 12371630]

37. Pekiner FN, Aytugar E, Demirel GY, Borahan MO. HLA-A, B (Class I) and HLA-DR, DQ (Class II) Antigens in Turkish Patients with Recurrent Aphthous Ulceration and Behcet's Disease. Medical principles and practice: international journal of the Kuwait University, Health Science Centre. Mar 7.2013

38. Imai H, Motegi M, Mizuki N, et al. Mouth and genital ulcers with inflamed cartilage (MAGIC syndrome): a case report and literature review. Am J Med Sci. Nov; 1997 314(5):330-332. [PubMed: 9365335]

39. Orme RL, Nordlund JJ, Barich L, Brown T. The MAGIC syndrome (mouth and genital ulcers with inflamed cartilage). Arch Dermatol. Jul; 1990 126(7):940-944. [PubMed: 2360844]

40. Greenberg MS, Pinto A. Etiology and Management of Recurrent Aphthous Stomatitis. Curr Infect Dis Rep. Jun; 2003 5(3):194-198. [PubMed: 12760815]

41. Cheng J, Malahias T, Brar P, Minaya MT, Green PH. The association between celiac disease, dental enamel defects, and aphthous ulcers in a United States cohort. J Clin Gastroenterol. Mar; 2010 44(3):191-194. [PubMed: 19687752]

42. Baccaglini L, Lalla RV, Bruce AJ, et al. Urban legends: recurrent aphthous stomatitis. Oral Dis. Nov; 2011 17(8):755-770. [PubMed: 21812866]

43. Kerr AR, Ship JA. Management strategies for HIV-associated aphthous stomatitis. Am J Clin Dermatol. 2003; 4(10):669-680. [PubMed: 14507229]

44. Ramos-Gomez F. Dental considerations for the paediatric AIDS/HIV patient. Oral Dis. 2002; 8 (Suppl 2):49-54. [PubMed: 12164660]

45. Rodenas JM, Ortego N, Herranz MT, Tercedor J, Pinar A, Quero JH. Cyclic neutropenia: a cause of recurrent aphthous stomatitis not to be missed. Dermatology. 1992; 184(3):205-207. [PubMed: 1392113]

46. Vigo G, Zulian F. Periodic fevers with aphthous stomatitis, pharyngitis, and adenitis (PFAPA). Autoimmunity reviews. Nov; 2012 12(1):52-55. [PubMed: 22878272]

47. Albanidou-Farmaki E, Deligiannidis A, Markopoulos AK, Katsares V, Farmakis K, Parapanissiou E. HLA haplotypes in recurrent aphthous stomatitis: a mode of inheritance? International journal of immunogenetics. Dec; 2008 35(6):427-432. [PubMed: 19046300]

48. Wray D, Vlagopoulos TP, Siraganian RP. Food allergens and basophil histamine release in recurrent aphthous stomatitis. Oral Surg Oral Med Oral Pathol. Oct; 1982 54(4):388-395. [PubMed: 6183631] 
49. Hasan A, Shinnick T, Mizushima Y, van der Zee R, Lehner T. Defining a T-cell epitope within HSP 65 in recurrent aphthous stomatitis. Clin Exp Immunol. May; 2002 128(2):318-325. [PubMed: 11985522]

50. Pacor ML, Di Lorenzo G, Martinelli N, et al. Results of double-blind placebo-controlled challenge with nickel salts in patients affected by recurrent aphthous stomatitis. Int Arch Allergy Immunol. Aug; 2003 131(4):296-300. [PubMed: 12915773]

51. Hay KD, Reade PC. The use of an elimination diet in the treatment of recurrent aphthous ulceration of the oral cavity. Oral Surg Oral Med Oral Pathol. May; 1984 57(5):504-507. [PubMed: 6587298]

52. Shim YJ, Choi JH, Ahn HJ, Kwon JS. Effect of sodium lauryl sulfate on recurrent aphthous stomatitis: a randomized controlled clinical trial. Oral Dis. Oct; 2012 18(7):655-660. [PubMed: 22435470]

53. Healy CM, Paterson M, Joyston-Bechal S, Williams DM, Thornhill MH. The effect of a sodium lauryl sulfate-free dentifrice on patients with recurrent oral ulceration. Oral Dis. Jan; 1999 5(1): 39-43. [PubMed: 10218040]

54. Lewkowicz N, Lewkowicz P, Dzitko K, et al. Dysfunction of CD4+CD25high T regulatory cells in patients with recurrent aphthous stomatitis. J Oral Pathol Med. Sep; 2008 37(8):454-461. [PubMed: 18318707]

55. Savage NW, Seymour GJ, Kruger BJ. T-lymphocyte subset changes in recurrent aphthous stomatitis. Oral Surg Oral Med Oral Pathol. Aug; 1985 60(2):175-181. [PubMed: 3162131]

56. Mohammad R, Halboub E, Mashlah A, Abou-Hamed H. Levels of salivary IgA in patients with minor recurrent aphthous stomatitis: a matched case-control study. Clinical oral investigations. Apr; 2013 17(3):975-980. [PubMed: 22814759]

57. Sun A, Chu CT, Liu BY, Wang JT, Leu JS, Chiang CP. Expression of interleukin-2 receptor by activated peripheral blood lymphocytes upregulated by the plasma level of interleukin-2 in patients with recurrent aphthous ulcers. Proc Natl Sci Counc Repub China B. Jul; 2000 24(3):116-122. [PubMed: 10943944]

58. Bachtiar EW, Cornain S, Siregar B, Raharjo TW. Decreased CD4+/CD8+ ratio in major type of recurrent aphthous ulcers: comparing major to minor types of ulcers. Asian Pac J Allergy Immunol. Jun-Sep;1998 16(2-3):75-79. [PubMed: 9876944]

59. Pekiner FN, Aytugar E, Demirel GY, Borahan MO. Interleukin-2, interleukin-6 and T regulatory cells in peripheral blood of patients with Behcet's disease and recurrent aphthous ulcerations. J Oral Pathol Med. Jan; 2012 41(1):73-79. [PubMed: 21736625]

60. Boras VV, Lukac J, Brailo V, Picek P, Kordic D, Zilic IA. Salivary interleukin-6 and tumor necrosis factor-alpha in patients with recurrent aphthous ulceration. J Oral Pathol Med. Apr; 2006 35(4):241-243. [PubMed: 16519772]

61. Dar-Odeh NS, Alsmadi OM, Bakri F, et al. Predicting recurrent aphthous ulceration using genetic algorithms-optimized neural networks. Advances and applications in bioinformatics and chemistry: AABC. 2010; 3:7-13. [PubMed: 21918622]

62. Kozlak ST, Walsh SJ, Lalla RV. Reduced dietary intake of vitamin B12 and folate in patients with recurrent aphthous stomatitis. J Oral Pathol Med. May; 2010 39(5):420-423. [PubMed: 20141576]

63. McCann AL, Bonci L. Maintaining women's oral health. Dent Clin North Am. Jul; 2001 45(3): 571-601. [PubMed: 11486666]

64. Volkov I, Rudoy I, Freud T, et al. Effectiveness of vitamin B12 in treating recurrent aphthous stomatitis: a randomized, double-blind, placebo-controlled trial. Journal of the American Board of Family Medicine: JABFM. Jan-Feb;2009 22(1):9-16. [PubMed: 19124628]

65. Gulcan E, Toker S, Hatipoglu H, Gulcan A, Toker A. Cyanocobalamin may be beneficial in the treatment of recurrent aphthous ulcers even when vitamin B12 levels are normal. Am J Med Sci. Nov; 2008 336(5):379-382. [PubMed: 19011392]

66. Keenan AV, Spivakovksy S. Stress associated with onset of recurrent aphthous stomatitis. Evidence-based dentistry. Mar.2013 14(1):25. [PubMed: 23579306]

67. Arikan S, Durusoy C, Akalin N, Haberal A, Seckin D. Oxidant/antioxidant status in recurrent aphthous stomatitis. Oral Dis. Oct; 2009 15(7):512-515. [PubMed: 19761497] 
68. Karincaoglu Y, Batcioglu K, Erdem T, Esrefoglu M, Genc M. The levels of plasma and salivary antioxidants in the patient with recurrent aphthous stomatitis. J Oral Pathol Med. Jan; 2005 34(1): 7-12. [PubMed: 15610400]

69. Cimen MY, Kaya TI, Eskandari G, Tursen U, Ikizoglu G, Atik U. Oxidant/antioxidant status in patients with recurrent aphthous stomatitis. Clin Exp Dermatol. Nov; 2003 28(6):647-650. [PubMed: 14616834]

70. Boulinguez S, Reix S, Bedane C, et al. Role of drug exposure in aphthous ulcers: a case-control study. Br J Dermatol. Dec; 2000 143(6):1261-1265. [PubMed: 11122030]

71. Boulinguez S, Sommet A, Bedane C, Viraben R, Bonnetblanc JM. Oral nicorandil-induced lesions are not aphthous ulcers. J Oral Pathol Med. Sep; 2003 32(8):482-485. [PubMed: 12901730]

72. Oh SH, Han EC, Lee JH, Bang D. Comparison of the clinical features of recurrent aphthous stomatitis and Behcet's disease. Clin Exp Dermatol. Aug; 2009 34(6):e208-212. [PubMed: 19549229]

73. Woo, SB.; Greenberg, MS. Ulcerative, vesicular and bullous lesions. In: Greenberg, MS.; Glick, M.; Ship, JA., editors. Burket's Oral Medicine. 11. Hamilton, Canada: BC Decker; 2008. p. 41-76.

74. Jurge S, Kuffer R, Scully C, Porter SR. Mucosal disease series. Number VI. Recurrent aphthous stomatitis. Oral Dis. Jan; 2006 12(1):1-21. [PubMed: 16390463]

75. Lewkowicz N, Kur B, Kurnatowska A, Tchorzewski H, Lewkowicz P. Expression of Th1/Th2/ Th3/Th17-related genes in recurrent aphthous ulcers. Arch Immunol Ther Exp (Warsz). Oct; 2011 59(5):399-406. [PubMed: 21805152]

76. Lewkowicz N, Lewkowicz P, Banasik M, Kurnatowska A, Tchorzewski H. Predominance of Type 1 cytokines and decreased number of CD4(+)CD25(+high) T regulatory cells in peripheral blood of patients with recurrent aphthous ulcerations. Immunology letters. Jun 15; 2005 99(1):57-62. [PubMed: 15894112]

77. Natah SS, Hayrinen-Immonen R, Hietanen J, et al. Increased density of lymphocytes bearing gamma/delta T-cell receptors in recurrent aphthous ulceration (RAU). Int J Oral Maxillofac Surg. Oct; 2000 29(5):375-380. [PubMed: 11071244]

78. Hietanen J, Hayrinen-Immonen R, Al-Samadi A, Trokovic N, Koskenpato K, Konttinen YT. Recurrent aphthous ulcers--a Toll-like receptor-mediated disease? J Oral Pathol Med. Feb; 2012 41(2):158-164. [PubMed: 21899597]

79. Gallo C, Barros F, Sugaya N, Nunes F, Borra R. Differential expression of toll-like receptor mRNAs in recurrent aphthous ulceration. J Oral Pathol Med. Jan; 2012 41(1):80-85. [PubMed: 21554403]

80. Saxen MA, Ambrosius WT, Rehemtula al KF, Russell AL, Eckert GJ. Sustained relief of oral aphthous ulcer pain from topical diclofenac in hyaluronan: a randomized, double-blind clinical trial. Oral Surg Oral Med Oral Pathol Oral Radiol Endod. Oct; 1997 84(4):356-361. [PubMed: 9347497]

81. Khandwala A, Van Inwegen RG, Alfano MC. 5\% amlexanox oral paste, a new treatment for recurrent minor aphthous ulcers: I. Clinical demonstration of acceleration of healing and resolution of pain. Oral Surg Oral Med Oral Pathol Oral Radiol Endod. Feb; 1997 83(2):222-230. [PubMed: 9117754]

82. Liu C, Zhou Z, Liu G, et al. Efficacy and safety of dexamethasone ointment on recurrent aphthous ulceration. Am J Med. Mar; 2012 125(3):292-301. [PubMed: 22340928]

83. Pilotte AP, Hohos MB, Polson KM, Huftalen TM, Treister N. Managing stomatitis in patients treated with Mammalian target of rapamycin inhibitors. Clinical journal of oncology nursing. Oct; 2011 15(5):E83-89. [PubMed: 21951751]

84. Gorsky M, Epstein J, Rabenstein S, Elishoov H, Yarom N. Topical minocycline and tetracycline rinses in treatment of recurrent aphthous stomatitis: a randomized cross-over study. Dermatol Online J. 2007; 13(2):1. [PubMed: 17498420]

85. Kerr AR, Drexel CA, Spielman AI. The efficacy and safety of $50 \mathrm{mg}$ penicillin G potassium troches for recurrent aphthous ulcers. Oral Surg Oral Med Oral Pathol Oral Radiol Endod. Dec; 2003 96(6):685-694. [PubMed: 14676759] 
86. Silverman S Jr, Lozada-Nur F, Migliorati C. Clinical efficacy of prednisone in the treatment of patients with oral inflammatory ulcerative diseases: a study of fifty-five patients. Oral Surg Oral Med Oral Pathol. Apr; 1985 59(4):360-363. [PubMed: 3858773]

87. Mimura MA, Hirota SK, Sugaya NN, Sanches JA Jr, Migliari DA. Systemic treatment in severe cases of recurrent aphthous stomatitis: an open trial. Clinics (Sao Paulo). 2009; 64(3):193-198. [PubMed: 19330244]

88. Thornhill MH, Baccaglini L, Theaker E, Pemberton MN. A randomized, double-blind, placebocontrolled trial of pentoxifylline for the treatment of recurrent aphthous stomatitis. Arch Dermatol. Apr; 2007 143(4):463-470. [PubMed: 17438178]

89. Tasher D, Stein M, Dalal I, Somekh E. Colchicine prophylaxis for frequent periodic fever, aphthous stomatitis, pharyngitis and adenitis episodes. Acta Paediatr. Aug; 2008 97(8):1090-1092. [PubMed: 18462461]

90. Fontes V, Machet L, Huttenberger B, Lorette G, Vaillant L. Recurrent aphthous stomatitis: treatment with colchicine. An open trial of 54 cases. Ann Dermatol Venereol. Dec; 2002 129(12): 1365-1369. [PubMed: 12536172]

91. Altenburg A, Zouboulis CC. Current concepts in the treatment of recurrent aphthous stomatitis. Skin Therapy Lett. Sep; 2008 13(7):1-4. [PubMed: 18839042]

92. Michael O, Goldman RD, Koren G. Safety of colchicine therapy during pregnancy. Can Fam Physician. Aug.2003 49:967-969. [PubMed: 12943352]

93. Calabrese L, Fleischer AB. Thalidomide: current and potential clinical applications. Am J Med. Apr 15; 2000 108(6):487-495. [PubMed: 10781782]

94. Cheng S, Murphy R. Refractory aphthous ulceration treated with thalidomide: a report of 10 years' clinical experience. Clin Exp Dermatol. Mar; 2012 37(2):132-135. [PubMed: 22007681]

95. Hello M, Barbarot S, Bastuji-Garin S, Revuz J, Chosidow O. Use of thalidomide for severe recurrent aphthous stomatitis: a multicenter cohort analysis. Medicine (Baltimore). May; 2010 89(3):176-182. [PubMed: 20453604]

96. Shetty K. Thalidomide in the management of recurrent aphthous ulcerations in patients who are HIV-positive: a review and case reports. Spec Care Dentist. Sep-Oct;2005 25(5):236-241. [PubMed: 16454100]

97. Jacobson JM, Greenspan JS, Spritzler J, et al. Thalidomide in low intermittent doses does not prevent recurrence of human immunodeficiency virus-associated aphthous ulcers. J Infect Dis. Jan 15; 2001 183(2):343-346. [PubMed: 11120935]

98. Altenburg A, Abdel-Naser MB, Seeber H, Abdallah M, Zouboulis CC. Practical aspects of management of recurrent aphthous stomatitis. J Eur Acad Dermatol Venereol. Sep; 2007 21(8): 1019-1026. [PubMed: 17714120]

99. O'Neill ID. Efficacy of tumour necrosis factor-alpha antagonists in aphthous ulceration: review of published individual patient data. J Eur Acad Dermatol Venereol. Feb; 2012 26(2):231-235. [PubMed: 22280510]

100. Ship. Socioeconomic status and recurrent aphthous ulcers. J Am Dent Assoc. Jul; 1966 73(1): 120-123. [PubMed: 5219641] 


\section{Key Points}

Recurrent aphthous stomatitis (RAS) is the most common ulcerative disease of the oral mucosa. Several etiological theories proposed are reviewed. Topical and systemic therapies that are used to manage RAS are also presented. 


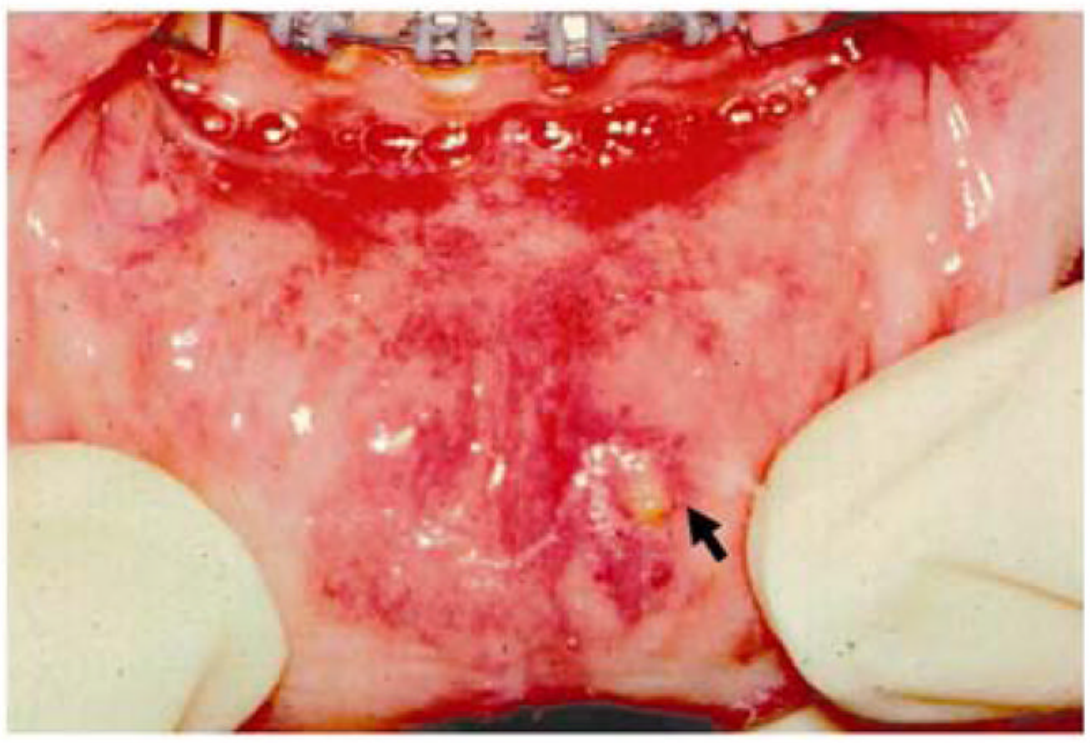

Figure 1.

Minor aphthous ulcer on the lower lip 

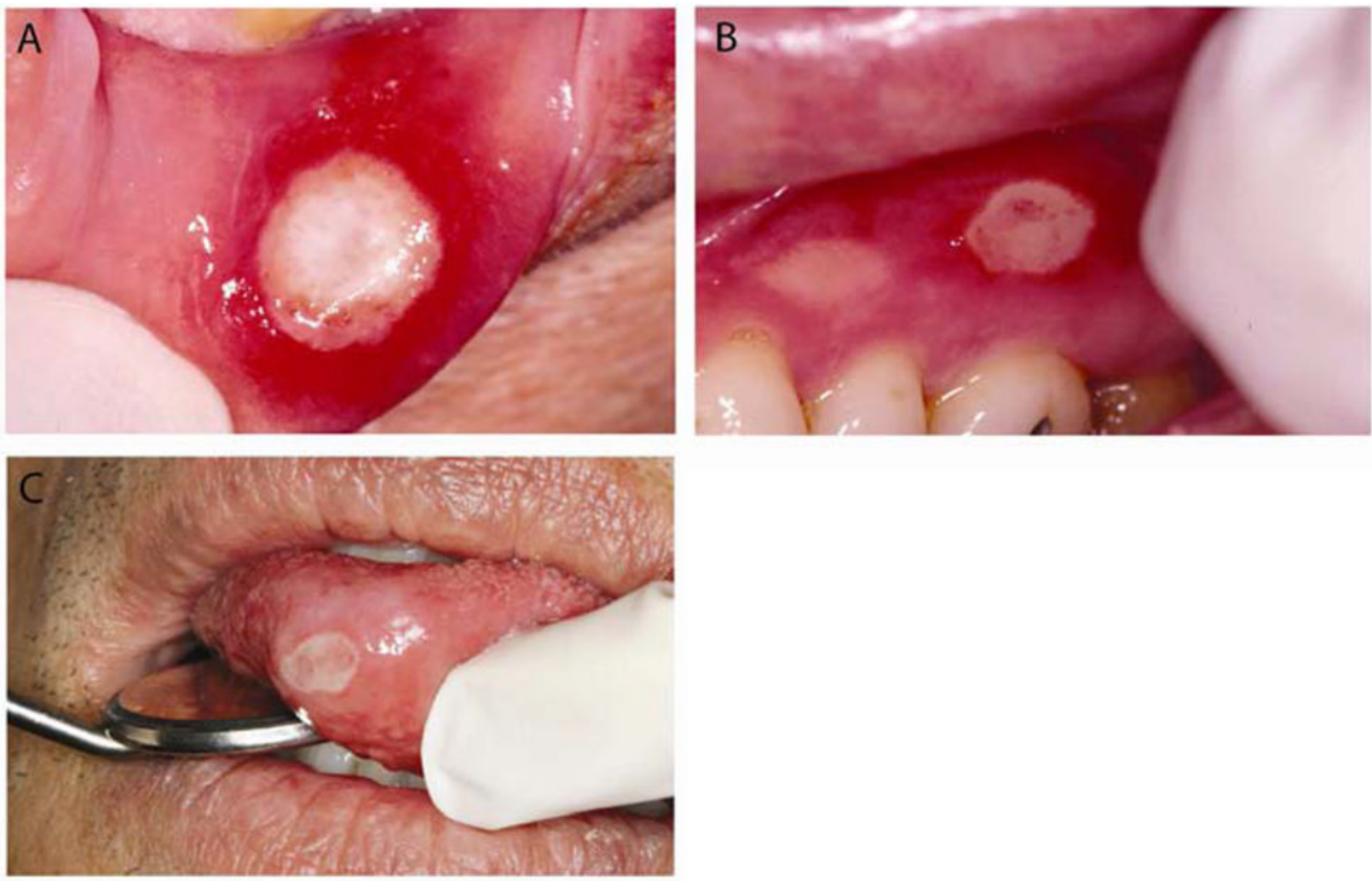

Figure 2.

Major aphthous ulcer on the lower lip (A), maxillary unattached gingiva (B) and anterior tongue $(\mathrm{C})$. The ulcers display characteristic erythematous halo and central yellowish-gray pseudomembrane. 


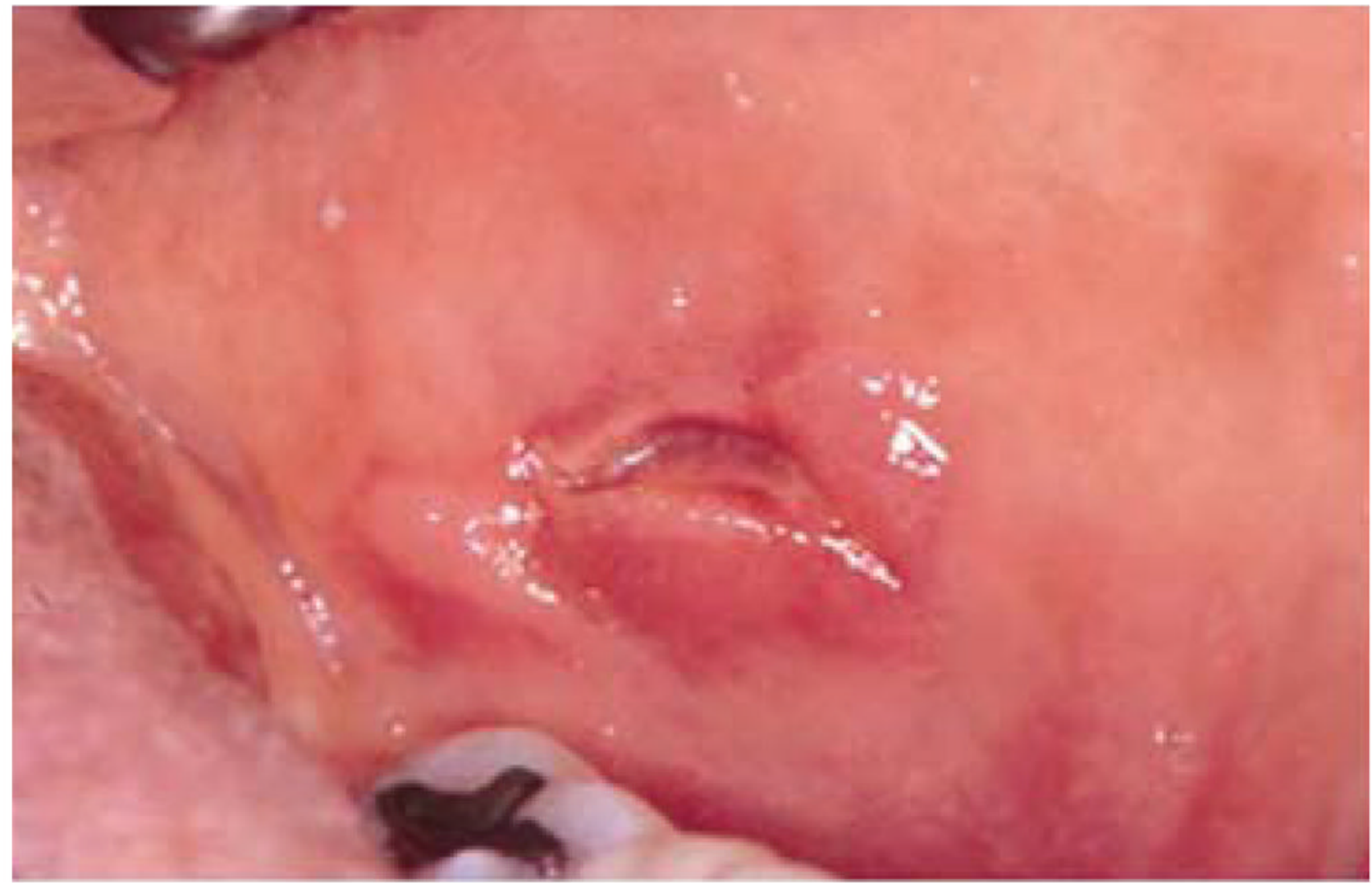

Figure 3.

Ulcer with indurated margin on the buccal mucosa of a patient with Crohn's disease. 


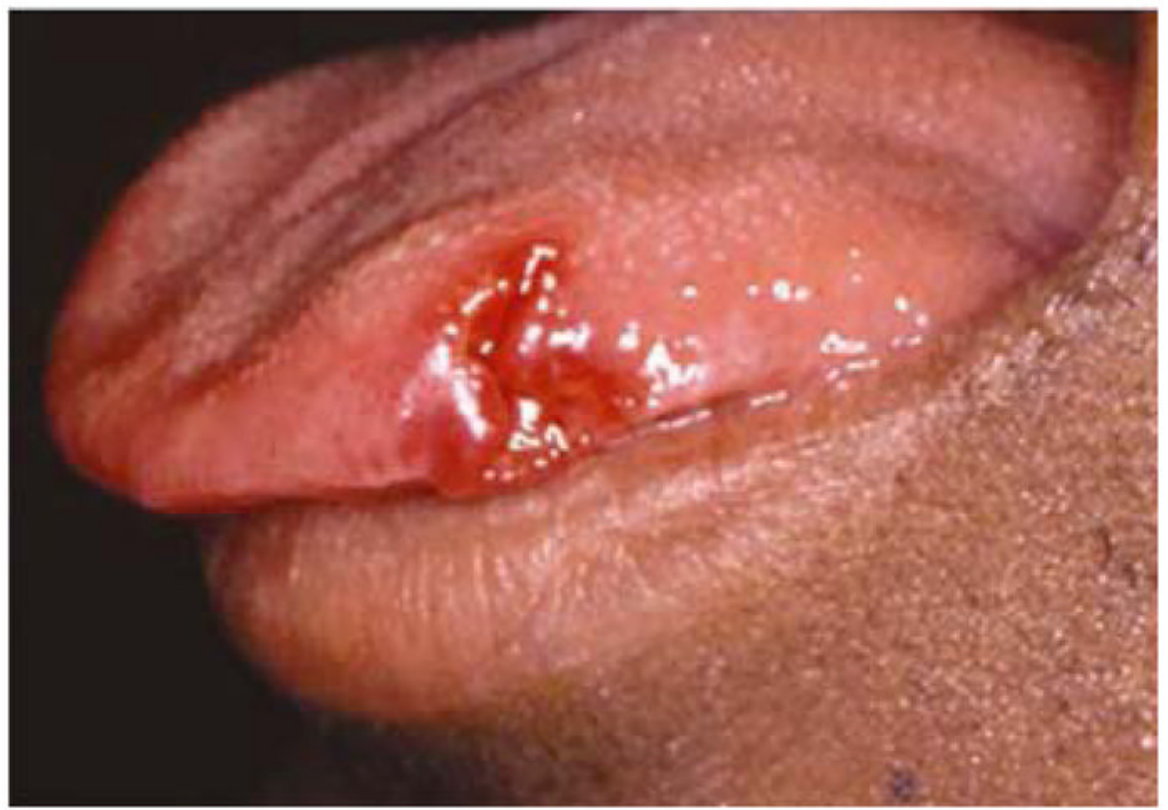

Figure 4.

Aphthous-like lesion in a patient with advanced HIV disease. 


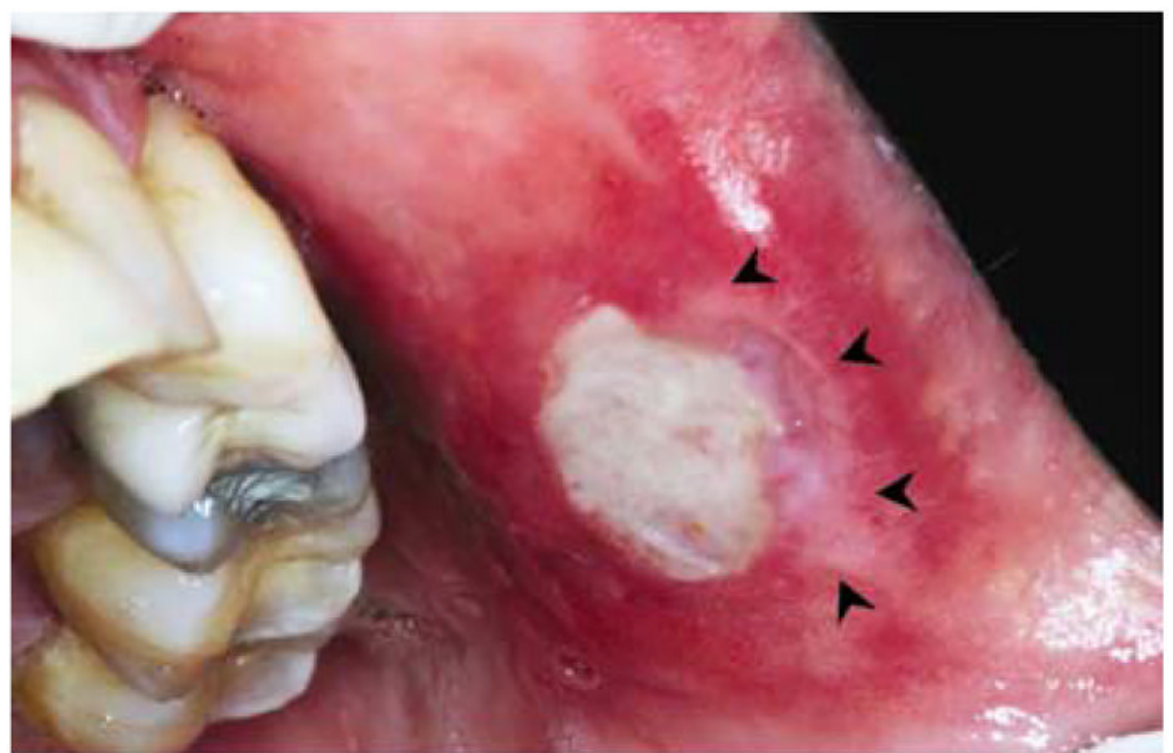

Figure 5.

Major RAS on left buccal mucosa responding to pentoxifylline therapy. Note the progressive healing and absence of pseudomembrane in a section of the ulcer (black arrowheads) 
Table 1

\begin{tabular}{lccc}
\hline & \multicolumn{3}{c}{ Types of Recurrent Aphthous Stomatitis* } \\
\hline & Minor & Major & Herpetiform \\
\cline { 2 - 4 } Gender predilection: & $\mathrm{M}=\mathrm{F}$ & $\mathrm{M}=\mathrm{F}$ & $\mathrm{F}>\mathrm{M}$ (usually) \\
Age of onset (years): & $5-19$ & $10-19$ & $20-29$ \\
Number of ulcers: & $1-5$ & $1-10$ & $10-100$ \\
Size of ulcers (mm): & $<10$ & $>10$ & $1-2$ (larger if coalesced) \\
Duration (days); & $4-14$ & $>30$ & $<30$ \\
Recurrence rate (months): & $1-4$ & $<1$ & $<1$ \\
Site predilection: & Lips, cheeks, tongue, floor of & Lips, cheeks, tongue, palate, & Lips, cheeks, tongue, pharynx, palate, \\
& mouth & gingiva, floor of mouth
\end{tabular}

* Adapted from: Porter SR, Scully C, Pedersen A. Recurrent aphthous stomatitis. Crit Rev Oral Biol Med. 1998;9(3):306-321. 
Table 2

\begin{tabular}{|c|c|}
\hline \multicolumn{2}{|r|}{ Etiological Factors Associated with Recurrent Aphthous Stomatitis* } \\
\hline \multirow{3}{*}{ Local: } & Trauma \\
\hline & Smoking \\
\hline & Dysregulated saliva composition \\
\hline \multirow{2}{*}{ Microbial: } & Bacterial: Streptococci \\
\hline & Viral: Varicella zoster, Cytomegalovirus \\
\hline \multirow{8}{*}{ Systemic: } & Behçet's disease \\
\hline & Mouth and genital ulcers with inflamed cartilage (MAGIC) syndrome \\
\hline & Crohn's disease \\
\hline & Ulcerative colitis \\
\hline & HIV infection \\
\hline & Periodic fever, aphthosis, pharyngitis, and adenitis (PFAPA) or Marshall's syndrome \\
\hline & Cyclic neutropenia \\
\hline & Stress; psychological imbalance, menstrual cycle \\
\hline \multirow{3}{*}{ Nutritional: } & Gluten sensitive enteropathy \\
\hline & Iron, folic acid, zinc deficiencies \\
\hline & Vitamin B1, B2, B6 and B12 deficiencies \\
\hline \multirow{2}{*}{ Genetic: } & Ethnicity \\
\hline & HLA haplotypes \\
\hline \multirow{6}{*}{ Allergic/Immunologic: } & Local T-lymphocyte cytotoxicity \\
\hline & Abnormal CD4:CD8 ratio \\
\hline & Dysregulated cytokine levels \\
\hline & Microbe-induced hypersensitivity \\
\hline & Sodium lauryl sulfate (SLS) sensitivity \\
\hline & Food sensitivity \\
\hline \multirow{4}{*}{ Others: } & Antioxidants \\
\hline & Non-steroidal anti-inflammatory drugs (NSAIDS) \\
\hline & Beta blockers \\
\hline & Immunosuppressive drugs \\
\hline
\end{tabular}

*Adapted from: Ship, II. Socioeconomic status and recurrent aphthous ulcers. J Am Dent Assoc. Jul 1966;73(1):120-123. 